\title{
TRADITIONS OF UNDERSTANDING IN PSYCHOANALYSIS
}

\author{
Henrik Enckell $^{7}$
}

\begin{abstract}
Psychoanalysts try to facilitate their patients' grasp and understanding of themselves. Since the mid-19th century, we have two conceptions of understanding. In one tradition, we need to suspect presented pictures and try to get "behind" facades in order to grasp the "true" self. In this tradition we get a hold of ourselves if we look for the origins: we need to see where we come from. In the other tradition we should not try to "tear off the masks", but start a dialogue with the text or person we try to understand. If we succeed in this, the truth "steps forward". In this conception we need to move on to goals and positions not yet attained. According to the general view Freud belongs to the first tradition. The author asks how we view understanding in modern psychoanalysis. Through a reading of (1) the Boston Change Process Study Group, (2) Peter Fonagy and Mary Target and (3) Veikko and Riitta Tähkä he concludes that we in psychoanalysis have moved from the first to the second tradition. He discusses what inferences we should draw regarding technique and theory, concentrating on the phenomena and concepts of interpretation and the unconscious.
\end{abstract}

Keywords: understanding, hermeneutics, moments of meeting, mentalization, the unconscious, interpretation.

\footnotetext{
${ }^{7}$ The Finnish Psychoanalytical Society; henrik.enckell@kolumbus.fi
} 


\section{Introduction}

Psychoanalysis has inevitably changed since its inception. It is, however, not easy to point out the most relevant dimensions of this change. Reviewers of the subject have usually noted - often after a certain lapse of time (Sandler, 1983) - that certain transformations have taken place. The perspective has usually been intra-psychoanalytical: psychoanalysts have looked at psychoanalytic texts and have noted in retrospect that things have changed.

I will approach the subject from a more specific and outside perspective. Most psychoanalysts would probably agree that they try to promote their patients' understanding and grasp of themselves. This, however, is not the aim of psychoanalysis solely as all humanistic disciplines have their motivation here: we read history, literature and cultural studies in order to understand who we are. It is not fully clear, however, how we gain understanding and what understanding means.

Since the mid- $19^{\text {th }}$ century there have basically been two views of understanding. (1) There are certain forces which make us subjugate parts of ourselves, and what we show others and ourselves are distortions of our "true nature". Understanding, in this tradition, is an attempt to go behind the presented picture. (2) We cannot go "behind" the presented meaning, but need to start a dialogue with it. Understanding, in this tradition, is the process in which the "horizons" of text and self meet. The differences between these views were much discussed in the 60's and 70's (for an overview, see Apel [1971]). The first view was adhered to by e.g. Jürgen Habermas (1971), and the most well-known proponent for the second perspective was Hans-Georg Gadamer (1975).

For these authors it was self-evident that psychoanalysis was part of the first tradition. Habermas (1971) and Paul Ricœur (1970) equated 
psychoanalysis with Freud, and although they had differing views on what understanding and grasping oneself mean, they both thought Freud was a master of "demystification". Freudian psychoanalysis is an attempt to go behind false illusions.

The aim of this paper is to see if this interpretation holds good also for contemporary psychoanalysis: has our view of understanding (and by that, the aim of psychoanalysis) changed?

I will start out with a description of the two views of understanding and interpretation. I have chosen to do this in the context of Paul Ricœur's theory. I will try to show how Freud's project of understanding was not only an attempt to demystify, but also to grasp the past. As representatives of modern ${ }^{8}$ psychoanalysis I have chosen (1) Peter Fonagy and Mary Target, (2) The Boston Change Process Study Group (BCPSG) and (3) Veikko and Riitta Tähkä. This sample can naturally be discussed. The reasons for picking out precisely these authors are: (1) The first two groups are very much cited, and they have thus had an undisputable impact in our field; (2) These authors represent trends which count as specifically modern: infant research, intersubjectivity, attachment theory, mentalization and object relations; (3) Although all three groups come from different backgrounds, they have come to fairly similar conclusions. The Tähkäs are not as well-known as the others, but there are reasons for their inclusion: Veikko Tähkä's principal work (1993) was an early contribution of themes that were later elaborated also by Stern's and Fonagy's groups, and the Tähkäs have made clarifications which are only hinted at in the others' oeuvres.

\footnotetext{
${ }^{8}$ The contemporary authors included have made their main contributions in the 90 's, and it may of course be said that there are still more "modern" ones. The chosen ones have, however, proven sustainable; they have had an influence during the whole of the two last decades. With the more recent authors, we do not know what their impact in the long run will be.
} 
So, the attempt in this paper is to look at these authors' conceptions of understanding. If there are two main traditions of understanding and interpretation, does modern psychoanalysis fit into the same tradition as Freud, or has our field changed in this respect?

What is the relevance of a comparison like this? As the perspective is philosophical, does it supply anything to psychoanalysis itself? I believe it does. As understanding is one of the most central concepts in psychoanalysis, and as it often has defined the aims of psychoanalysis, there are reasons to clarify where we stand in relation to it today. If a change has taken place: are there conclusions to make regarding psychoanalytic theory? Secondly, our view of understanding (and by that, the aim of psychoanalysis) certainly influences technique; are there inferences to make concerning our method of treatment? These questions will be addressed in the discussion.

\section{The two views of understanding}

Ricœur (1970) pictures understanding from two perspectives, topography and temporality. In both dimensions, the two traditions of understanding stand in opposition to each other.

In the topographical picture we have different "layers" of meaning. We have the obvious or manifest sense. "Below" or "behind" the manifest meaning we may have a latent and hidden sense. Understanding, in this picture, is the act of reaching the hidden sense through the manifest meaning. We call the method to attain this end interpretation. Understanding and interpretation are dependent on each other: We need interpretations since the full meaning of texts do not immediately show; to interpret is to reach for the hidden meaning; when we succeed in this, we understand. 
There are, however, different conceptions of interpretation. In the first tradition, the manifest meaning is a disguise. Subjects and texts thus need to be suspected. Interpretation is a tearing off of the masks. This, in Ricœur's words, is the hermeneutics of suspicion.

In the second tradition, the interpreter relates to the text in another spirit. The full meaning is not immediately here, but the interpreter may trust the text will speak in case one respects it in its own right. If one wants to interpret, one needs to start a dialogue. If one has the patience to listen, the hidden meaning will step forth. This, in Ricœur's terms, is the hermeneutics of faith.

Topographically, in the first tradition interpretation is thus demystification. Representatives of this view are Marx, Nietzsche and Freud. In the second tradition interpretation is a dialogue in which the hidden meaning evolves. Representatives of this view are Bultmann and Eliade

The temporal dimension of understanding is linked to reflection. Parts of our lives as well as our cultural heritage (parts that once were ours) are lost, and parts of our potentials have never become actualized. To grasp these lost or never attained aspects we need to reflect. The objects of reflection are remnants - through symbolic traces of ourselves and our ancestors we may grasp a fuller picture of who we are.

Reflection has a direction. In the first tradition we gain a hold of ourselves in turning back. If we find our origins, we find ourselves. The structure of this conception can be found in The Interpretation of Dreams (Freud, 1900, pp. 542-49). In dream interpretation we find the beginnings. We find the primary process, i.e., the first mental functional principle. We come to the first station in the psychical apparatus, i.e., the sensual perceptions. And we come to the temporal past as all unconscious wishes have an infantile root. As Freud notes, all three 
aspects are part of the temporal dimension. When we reflect on dreams we thus turn back. Reflection is an art of remembrance, an archaeological enterprise.

In the second tradition, again, we reach for our full meaning by moving forward. Our meaning is not in our past; the meaning of today will show only tomorrow. Reflection, in this tradition, is the becoming of one's self, and this becoming is dependent on a "moving on". The structure of this model can be found in Hegel's Phenomenology of Spirit (2018/1807) (many today see Hegel as outdated but his picture of the "moving on" of reflection is illustrative and does not imply an acceptance of his metaphysics). In order to become who we are, in order to owe ourselves, we need to go, and look, ahead. Reflection is an art of turning forward, a teleological project.

\section{The case of Oedipus Rex}

As illustration I have chosen Oedipus Rex (studied also by Ricœur in 1970). Since the play is well known, I will not go into the details. Suffice it to remind that Oedipus Rex begins with the plague of Thebe. The audience is not told at the outset, but everybody knows the precedents: the plague is a curse. Oedipus (the hero who makes the story move), however, is ignorant. He does not know his background, and by that his identity. He does not know how the main characters of the drama are related, and by that his guilt. The story of the play is Oedipus' way of relating to the problem. On the one hand he tries to find the source to the plague, irrespective of the other characters warnings. $\mathrm{He}$ strives toward the truth. On the other hand he "turns a blind eye" (Vellacott, 1971; Steiner, 1985; Zachrisson, 2013) towards the reality of his past deeds, "he does not see". Oedipus on the one hand strives 
towards the truth; on the other hand he conceals his own responsibility. In the end the truth evolves. Fate could not be evaded. All the characters tried to fight it, but it was a given: Oedipus, as a representative of the conditio humana (as he was born human), had to kill his Father and marry his Mother.

As Oedipus Rex has been a model of dramatic art, it has been interpreted in uncountable ways. Some of the readings are archaeological, others are teleological; most are a combination of both. Since I here want to show the structure of the two opposite models of understanding, I will only delineate fairly pure examples of both.

In the first tradition, Oedipus Rex is a tragedy of antecedents and concealment. Oedipus does not want to see his guilt; the reality of his deeds lies behind an illusion of innocence and proudness (which need to be suspected). In the beginning of the play we are at a certain point (the plague), and the drama gets started by a look towards the source of the situation. The move of the play is a look back. This can be seen in three aspects. (1) In the play we (with Oedipus) search for the things already happened. We look towards the deeds already done. When we look for the source of the situation at hand (the plague), we look for the precedents. (2) Oedipus is ignorant of his identity. When he hears about the origins (how he had been saved by the shepherds; who his true parents are), he finds out. In the drama Oedipus finds himself in finding his beginning. (3) Oedipus Rex tells about the "already given". The gods had spelled a curse, everything was decided - the story was determined at the outset. Our fate (to kill one's Father and marry one's Mother) is given at our birth.

In this reading we suspect what shows since Oedipus tries to conceal the truth. The story is a move back: we look towards the things that already have happened, we find the identity in this look to the 
origins, and the whole story is a narrative of the destiny of Man. Oedipus Rex is a story of turning to the origins.

In the second tradition, Oedipus Rex is a tragedy of evolving consciousness. We start with a lack of knowledge. Oedipus does not want to stay in ignorance, but initiates a dialogue with potential informants. The play starts at a certain point, and involves a move forward. Oedipus treads a road towards something not yet known. The goal is consciousness of oneself, or: the goal is to become oneself. This is possible if one, like Oedipus, turns towards the things ahead, towards the goal not yet attained, towards the consciousness not yet here. This demands courage, and this is the reason we - as Hölderlin (1952) has noted - look at him as a hero: Oedipus has the courage to take hold of himself. It takes place in a dialogue with others. It is a process of moving on. Oedipus Rex is a story of a teleological enterprise.

In the first reading we look back, in the second one we move forward ${ }^{9}$. Which direction do we take in psychoanalysis?

\section{Freud's Model}

Interpretation is a method to enhance understanding. Psychoanalysis is a subspecies of interpretation (as we have interpretation in many fields). In the clinical situation we meet verbal and nonverbal narratives the grasp of which we try to facilitate. This

\footnotetext{
${ }^{9}$ In Zachrisson's (2013) reading the tragedy of Oedipus Rex consists in the combination of both strivings: Oedipus both wants to move ahead and conceal the truth. This is the tragedy also of the analytical patient's situation - on the one hand we have the strife to consciousness ahead, on the other hand we want to regress to ignorance. In this interpretation the ingenuity of Sophocles' play lies in the description of an insoluble conflict of archaeological and teleological tendencies.
} 
attempt can be described in various ways. First I will give a sketch of Freud's model.

Freud's work has, just like Oedipus Rex, been read in uncountable ways. If one forces Freudian psychoanalysis into the procrustean bed of one view only, one certainly does violence to it. However, Ricoeur's (1970) book on Freud shows the profundity of his archaeology. This does not exclude teleological trends. Freud's archaeology shows in his model of the workings of the psyche, but also in his conception of the psychoanalytical method.

I already referred to the regressive pattern in dreams. In The Interpretation of Dreams (Freud, 1900) the archaeological structure is obvious. Throughout Freud's oeuvre one may, however, see a certain tendency: phenomena which look progressive turn out, at a closer look, to be regulated by a hidden turn back.

Identification is often seen as a developmental process. This interpretation is certainly correct, but in The ego and the id (Freud, 1923) we learn that we introject, and later identify with, our primary objects as a refusal to give them up. Basically, identification is an attempt to consolidate and save our very first ties. "Below" the developmental process we have an attempt to fixate an original state of affairs.

Usually we think that ideals are goals not yet attained. Ideals tell us about a capacity to strive forward. This interpretation is naturally correct, but from On narcissism: An introduction (Freud, 1914) we learn that "behind" the teleological striving there is an opposite trend. Ideals are not, in the last reckoning, images of a state ahead, but the projection of our very first position. We try to attain the ideal in order to get back to infantile narcissism. Ideals are not a way forward, but an attempt to get back to our past. 
Religious ideas could be seen as illusions of something to reach for as religious narratives often tell about a "Kingdom come." A spiritual life is moreover often seen as a road to ever higher levels of consciousness. In The future of an illusion, Freud (1927) however shows the hidden opposite. Religious illusions are an attempt to save our primary objects and the safety they may offer; religious illusions are a return of repressed history. Religion is, in the end, remembrance.

The drive makes us feel, think and do what we do. As Freud says in Beyond the pleasure principle (1920) we think of drives as a force which makes us move on. He refers to Goethe's Faust (p. 42): the drive is the thing which "ungebändigt immer vorwärts dringt" ("presses ever forward unsubdued"). There is however something "beyond" this “drang vorwärts". Freud's 1920 essay may in fact be seen as a study on the opposite of a teleological picture. Life is not directed forwards, but only a detour to our beginnings. In the end the drives take us to the time before life started (as death is the state before organic life was born), or as in the myth of The Symposium: we strive back to the time when we were still united with our doubles. "Beyond" the appearance of life drives we have the silent move back to death.

If one can discern a Weltanschauung in Freud's theoretical constructs, it seems to be an archaeological one. We believe we move forward, but in fact we hark back. Our basic regulatory principle is a striving to the beginnings.

This view informs also Freud's picture of the method. It shows in his metaphors. The psychoanalyst is an archaeologist (Freud, 1901, p. $274 ; 1930$, p. $69 ; 1937$ b, p. 259): we dig out the historical remnants of the patient's history, we go through the later strata to the hidden layers of the past etc. To Freud, we look towards the traces of history (i.e., the unconscious layers behind infantile amnesia). And what is more: this is 
all we do. Freud (1919, p. 160) makes it very clear that we should keep within the confines of laying the hidden strata (i.e., the structural remnants of history) bare. The psychoanalyst should only analyze. $\mathrm{He}$ certainly shouldn't synthesize. If he synthesizes, he steps outside his given mandate.

Beside this archaeology we have, however, also an implicit teleology. According to Ricoeur (1970, pp. 483-493) it may be most obvious in the concept of sublimation: a process that seeks a way forward (a new aim) for the drive. There is teleology also in the operative concepts of technique as we try to foster a higher degree of consciousness - Freud in fact compares the psychoanalyst to the truthseeking Oedipus (Freud 1900, p. 262). One may also discern a dialectics between archaeological and teleological views: Nachträglichkeit e.g. is a temporal movement both forward and backward.

However, in Freud's work the archaeological trend is certainly the strongest one. This may be seen in the frames of his scientific work. Psychoanalysis has been said to start with The Interpretation of Dreams. Freud's (1940) last major text was An Outline of Psychoanalysis. These books thus mark the beginning and the end of Freud's lifework. Both end with the word "past."

\section{Contemporary models}

After Freud there has naturally been a long way to the contemporary scene. I will, however, go directly to the modern authorships, for various reasons. (1) We are most preoccupied with models we use today; (2) Comparisons of distant periods offer contrasts we do not have in authorships close to each other; (3) To encompass authorships in between would demand too much space. The main 
question is: how do we today stand in relation to past and future in psychoanalytic conceptions of understanding?

\section{The Boston Change Process Study Group}

The Boston Change Process Study Group (BCPSG) was formed some twenty years ago. The group's project is, as its name conveys, to study change in psychoanalysis and psychotherapy. It may also be said to study the curative factors of psychoanalysis.

I will go into the group's Non-interpretive mechanisms in psychoanalytic therapy: The "something more" than interpretation from 1998. This is a "pilot study" with the aims of describing the clinical conditions of change and the theory informing this picture. The paper is one of the most cited psychoanalytic contributions from the last twenty years. Many readers remember it as the "moments of meeting" paper.

As to the theoretical underpinnings, the BCPSG draws on mainly two conceptions. They see the therapeutic relationship as a "field" in which both agents are intertwined; the ways of one is dependent on the ways of the other. Secondly, the BCPSG stresses the importance of so called "procedural" knowledge. Procedural memory is - as is wellknown - not a memory with a certain content, but knowledge of "how to do things", be it in the motoric or interpersonal realm. Procedural knowledge is like grammar in language. Most of us cannot describe but perhaps a few grammatical principles. However, we "know" them by use. Grammar is the implicit knowledge of what to do with words; it draws the confines of what we can do with them.

The "field" of the therapeutic relationship is regulated by shared procedural knowledge, specific for this relationship. Both agents know 
the "grammar" of being together. The aim of psychoanalysis is to supply the conditions for a change or a "widening" of this "grammar." The widening is dependent on certain conditions in the interpersonal field.

Patient and analyst mostly follow ordinary but idiosyncratic "rules:" one thing follows another in a "business as usual" way. Then the atmosphere gets more "dense," the analyst gets a feeling something is approaching, and he often gets uneasy. The patient says, or does, something unexpected. The gesture is directed to the analyst, and it does not conform to the usual relational grammar. It is an "opening:" an application of a new rule and a new kind of invitation. The patient may suddenly ask: Do you love me? The BCPSG calls this a "now moment," and compares it to kairos in Greek mythology: a point where you may seize the situation. In case you do, destiny may change. This conveys the feeling of the analyst: "something important is happening, something may change, but this change is dependent on my answer."

If the analyst wants to "seize the moment," he cannot answer in preformed ("business as usual") phrases. As noted, in the now moment the patient approaches the analyst according to a rule that is both new and personal. The analyst has to answer reciprocally. This is the reason for his feeling bewildered. He cannot lean on principles already known, and he has to be personal. He does not have to expose personal feelings or thoughts, but he has to let his answer be informed by his very personal reaction to the very comment of the patient. In this sense it needs to be both new and personal. In case the analyst is able to meet the patient in this way, a "moment of meeting" ensues.

A "moment of meeting" has consequences. The patient made an approach in a new "grammar," and had the experience of sharing this with the analyst (since the analyst has met her in this same modality, from his own perspective). This leads to a possibility for the patient. 
Perhaps the patient will not change her way of speaking or being, but $a$ change has become a possibility. Or, the possibility has become a reality. The "moment of meeting" actualizes a new possibility of being in the world.

This model differs from the one presented by Freud. The BCPSG does not think of psychoanalysis as a digging for hidden layers behind the repression barrier. They do not consider the retrieval or construction of early, episodic, memories essential. As they say in the title of their paper: they look for the "something more than interpretation." They do not define "interpretation," but one may infer a classical Freudian conception: interpretation is the attempt to illuminate a hidden and latent content behind or below a manifest surface. This is not what the group proposes. The BCPSG does not look for the structural remnants of history. They do not speak for a psychoanalysis turned towards our origins.

Does memory have any place in this model? To the BCPSG change does not take place in the episodic, but in the procedural, domain (change does not take place in "words," but in the "grammar," of the psyche). Procedural knowledge is a "memory" since it tells about my history: my "grammar" of doing something tells about my past circumstances. The BCPSG is not, however, interested in this historical background. It is noteworthy that they do not speak of procedural memory, but of procedural knowledge. Their focus is not on the temporal background. Their focus is on the conditions of change. They thus look ahead.

This can be seen in two respects. The group's focus is on development. If your model is developmental, you usually look at the steps ahead (instead of the antecedents). Secondly, there is a teleological fundament in the "thing" the BCPSG tries to facilitate. Freud's project was to search for psychic reality (the crystallized 
unconscious, the impulses "at bottom"). The BCPSG does not look for this reality, but for possibilities. A possibility is not reality, but a "thing" which may open up some scenery. Possibilities are about the future, or, possibilities open up a future. The BCPSG tries to help the patient move on; they try to build the conditions for something ahead. Their look seems thus to be in the opposite direction than Freud's.

\section{Peter Fonagy and Mary Target on mentalization}

Peter Fonagy and Mary Target may be best known from their joint work on mentalization. They have presented their findings in a series of four much read papers (Fonagy and Target, 1996, 2000, 2007, Target and Fonagy, 1996) and a book (Fonagy, Gergely, Target and Jurist, 2002). The papers present a developmental line, its aberrations, and its facilitation.

Fonagy and Target basically describe the development of an implicit theory of mind. How does the child come to understand the relation between mind and outer reality: what is the reality status of feelings, thoughts and beliefs, and how does it change during growth?

The child first believes that all people share the same thoughts. When he has a conception, all others have this same knowledge. Moreover, the belief feels real in a concrete sense: the ideas I have are equivalent to outer reality. In case I have a fear there is a lion under the bed there really is a lion lying there. Ideas are not considered ideas in their own right but are replica of facts of the world. This is the equivalent mode. Playing may feel dangerous at this stage since all evolving (and disturbing) feelings tell about threats "really there."

At the following step play feels safer. It still demands, however, a clear frame. If the child knows that now we are "only playing," he 
separates this fantasying activity and its concomitant world from outer reality. The pretend world needs to be clearly separated in order not to break down. In case the border to the outer world seems permeable, the child easily regresses to the equivalent mode. In "held" and separate play anything may be fantasized. This is the pretend mode.

The third step is a combination of the preceding ones. The mind was "set free" already in the pretend mode: it was possible to play with thoughts and to let the mind go its own ways. However, the condition was the isolation from outer reality. In the third step the fantasying activity may be applied also in the world. This is related to a new comprehension of mind. Feelings, thoughts and beliefs are understood to be precisely this: they are not facts about the world, all people do not share them, and they are understood to be perspectives. With this step the child may start to "play with reality," i.e., he may try out different thoughts on the reality "out there." This is the reflective, or mentalizing, mode.

Development to mentalization has conditions. When the child is in the throes of a feeling, the caregiver usually "mirrors" it, i.e., she reflects the feeling state in her (usually facial) expression. She gives the feeling an expression or representation. However, the "mirror picture" is not an exact replica. In her expression the mother includes a certain distance from the feeling: she might exaggerate the valence of the affect or she might show a slight irony. Through this distance (called "marking"), the mother shows that this is a representation of the feeling: I am not in the throes of the affect even though I share it, I offer the "picture" of it. This response has its own conditions: the caregiver needs to be able to identify the feeling, she needs to be able to contain it, and she needs to developmentally be "one step ahead." If the mother is able to offer these affect representations in this way the child may build up 
some "representation storage." In the end an understanding that representations are precisely this, i.e. representations, evolves.

Now, what is a "representation"? Fonagy's and Target's use of the word speak for its most frequent meaning. When I know that something in my mind is a representation, I (implicitly) know it to be an instrument. It is like an optical device; a perspective, a perspective through which something looks as it looks. In case I change perspective, things look different. At this stage the child understands (implicitly again) that people have different states of mind, i.e., they have different representations, i.e., they see things from different angles, i.e., they see different things.

This is naturally a huge developmental step, and Fonagy and Target (2007, p. 929-30) enumerate some of its advantages. When the child understands that other people have minds of their own, he can learn to read them, and this makes people more predictable (and the child becomes more independent). Further, the child is not anymore at the mercy of outer reality, but has the buffer of knowing that this state of mind is a perspective, and it could also be otherwise, things could be seen in another light. This does not mean that thinking and feeling would be "only playing" with no real consequences (as in the pretend mode), since the feeling or thought is a perspective on reality. The state of mind is not isolated from the outer world; it has to be taken seriously. Fundamentally, the mind's reality status has changed. The feeling or thought I have is not an actual "thing", it is not a fact in the sense that outer realities are facts. My state of mind is a possibility. This is the developmental goal Fonagy and Target write about, and its central place in their contribution can be seen in the title of their paper series: "Playing with reality." 
The goal of normative development is also the goal of psychoanalytical treatments. In order to get there, Fonagy and Target delineate some principles of technique. They note, in the description of a borderline case, (Fonagy and Target, 2000, p. 870) that interpretations "in the classical sense" do not work. They also say that thinking about the past does not help much (ibid., p. 867). What helps is what they call "small interpretations" (Fonagy and Target, 2007, p. 932): thinking (aloud) around the feeling state the patient is in. It resembles the mother's mirroring in being a representing activity. The analyst (like the mother) offers a picture of the patient's state of mind. Small interpretations also include a thinking (aloud) of the things that might have triggered the feelings at hand. As Fonagy and Target say (ibid.), small interpretations are about the same as what we classically call "clarifications."

Two conclusions are to be made. The first concerns theory. As with the Boston group, the mentalization theory is a developmental one. Fonagy and Target speak for a certain developmental line and goal, and in that respect they put their focus on "things ahead." But there is more to it. The goal they head at is the facilitation of potentiality, the ability to conceive the mind as an organ of possibilities. A possibility is a "thing" which opens up a view not here yet. It is a sight of what could be. It is not about a preformed reality. It is about the future, or it opens up this future.

This shows also in the conclusion about technique. As noted, in order to help the patient reach the developmental goal, "classical" interpretations do not help. "Classical" may here be understood as "Freudian" - i.e., attempts to reach a reality "behind" the presenting picture are not helpful. It is not helpful to search the past. In another paper Fonagy (1999, p. 220) is very explicit: "therapies that strive for a recapture of memory worship a false god. Psychoanalysts ought 
carefully and consistently to avoid the archaeological metaphor." We should not try to look back. Or, as Fonagy and Target (2007) write in their last paper on mentalization (p. 921), we should focus on the facilitation of a new experience instead of the old ones. We should turn ahead.

\section{Veikko and Riitta Tähkä}

Veikko Tähkä started out from an ego psychological orientation but came to take in object relational elements. Riitta Tähkä has elaborated and developed Veikko Tähkä's findings. The Tähkäs have published separately but I will present them as an undivided whole as their contributions fit in so well with each other.

In his magnum opus, Veikko Tähkä (1993) presents a developmental line as well as an application in relation to psychopathology and psychoanalytic treatment: what are the characteristics of each level of pathology and which phase-specific therapeutic means may set a new development going.

To help the patient back to the developmental track is not easy. In the area of fixation the patient has once failed; for some reason he has not, in this field, been helped to move on. The analyst has to offer understanding, and the kind of understanding needs to be adapted to the patient's needs: different levels of pathology require different kinds of understanding. Veikko Tähkä is best known from his conceptualization of borderline pathology. For the borderline patient the other, including the analyst, is a provider of (mostly soothing and pacifying) functions (the other is not an individual in his own right). The patient is not able to produce these functions by himself, and is thus desperately in need of somebody to provide them for him. 
At this level of pathology, the psychoanalytic cure is the provision of conditions for a resumed identification process: in case the patient can take on the lacking functions, he becomes (in respect to these functions) independent, and at a certain point he can take a leap to an individualized way of relating. What are the conditions for resuming the developmental process?

The analyst needs to be able to identify the patient's experience, i.e., he needs to apprehend the feeling state of the patient. He needs to be able to put this experience in words; he needs to be able to describe the experience from the patient's point of view. The description should moreover bear witness to the fact that the analyst in this area is developmentally "ahead" of the patient: the analyst should be able to give his description in a form the patient has not yet been able to find by himself. The description should thus be of the patient's experience and from the patient's perspective, but it should spring out from a formgiving function the patient does not yet "have". Tähkä calls this intervention an "empathic description".

The analyst is first a transference object, i.e., an object seen in the light of the interrupted development. This experience is without alternatives: the patient is at the mercy of his representations at hand, and due to the developmental arrest he cannot but repeat his one and only way of experiencing the other. In case the analyst manages, along the lines above, to grasp the patient's transference experience, the patient may feel found in a new way. This may become a turning point.

As noted, the patient is stuck at his fixation point. He has not dared to tread the developmental line again - after all, he has once failed in this domain. If he now would try to be with the other in a new way, how should he do it? What are the guarantees that it wouldn't be a disaster? If he feels found in a new way, he may, however, feel that 
someone is with him. If someone is with him, he may be ready to take the risk of moving ahead. At these points, a developmental relationship may be born. The analyst becomes a developmental object, i.e., an object in relation to whom the patient dares to risk experiential modes he has not had the courage to try before.

The raison d'être of psychoanalytic treatment is thus the developmental relationship: change takes place here. The curative factors of psychoanalysis are identical to the conditions of this relationship. As stated, the patient needs to feel that the analyst is with him. This does not mean adaption to the patient's transference wishes. These wishes are closed, and in case they are fulfilled, nothing happens. Instead, the analyst needs to see the potential of the patient, the "developing child" in him. In case the patient feels found he may open up to what Riitta Tähkä (2000) has called the "developmental illusion." In this illusion he does not demand a specific response from the analyst. He relates in a new way, and becomes most vulnerable. Being in the developmental illusion, he senses the possibilities at hand. At the same time he knows the risk that he will not succeed in his new moves, and there is also the danger that the indispensable presence of the analyst fails. If everything goes well, the patient has the courage to trust the experience of presence: if this is possible, two things follow. First, the world of possibilities (the developmental illusion) opens up. Second, new developmental steps become something one can think about. In short, a future is born.

Riitta Tähkä (ibid.) makes it clear that in the domain of the developmental illusion one should abstain from interpretations. Interpretations are attempts to go "behind" a façade, but in the area of developmental illusions there is nothing to be deciphered. In case one tries to interpret the new possibilities, they break down. The illusion 
should be shared. The developmental illusion does not point to the past (like the transference illusion does), but only to the future. Or, the future, and by that what is essential to the psychoanalytical cure (i.e., the vitalization of inherent potentials) becomes possible in the field of developmental illusions.

As to this theory's place in relation to the two models of understanding, the picture seems clear and come close to the conclusions made by the Boston group and the work of Fonagy and Target. The Tähkäs' model is a developmental one. They speak for a certain goal. The means of getting to this goal is the facilitation of an experiential mode in which possibilities step forth. The Tähkäs thus speak for the facilitation of a world ahead.

This concerned the overall theory of the Tähkäs. The same teleological turn may be seen in their view of the psychoanalytical method. Often one should not go for the past or the world "behind". This may work with structurally developed people, but in case the patient has not reached object constancy there is nothing "behind" the experience (as these patients do not use repression). Interpretations are not emotionally meaningful. "Empathic descriptions" again (which may work) are not attempts to reach a reality behind a façade, and they do not look for a genetic background. For the Tähkäs, understanding is not mainly a look back. It is a look forward, and this concerns both theory and technique.

\section{Discussion}

I started out from the question as to what kind of understanding we have in psychoanalysis. Two models were described. In one, understanding is an attempt to get behind a deceiving façade: this view 
is a search for the origins, i.e., a look back. In the second model understanding is a result of a dialogue: one tries to facilitate a view or meaning ahead. Freud belongs to the former tradition; the Boston and Fonagy groups as well as the Tähkäs adhere to the latter one. This shows in the conception of psychoanalytic technique and the view of the aim of psychoanalysis. We should try to help our patients get grip of their potentials, help them find possibilities once lost, and help them turn from repetitious transference to development ahead. This is a look forward.

A turn thus seems to have taken place. One may ask when all this happened, and for what reasons? One of the major forces of change is probably Donald Winnicott whose elaboration on play and potential space set the stage for the contemporary authors' Weltanschauung. One may discern traces from Wilfred Bion as well. Since Bion focused on the facilitation of new functions (instead of e.g. unconscious contents), he cleared the way for conceptions like procedural knowledge. And the first inter-subjectivists are naturally also important here. One reason for the turn may be experiences from the treatment of patients with severe psychopathology. Anyhow, this probably does not fully explain the change; extra-analytical cultural determinants supposedly also lurk in the background. This, however, should be the subject of another paper.

What are the consequences of the turn? And: does the turn imply consequences we have not yet fully realized? As Sandler (1983) noted, explication of changes often takes time. Clinical technique changes first; explicit theory lags behind. I will make a couple of suggestions as to what these explications could be. I will focus on one clinical and one theoretical issue.

Even if Freud substituted the topographical model for the structural one, topography still permeates our clinical theory (Sandler 
and Sandler, 1983). It may also be noted that the structures of mind often are pictured as places or agents in space. The topographical metaphor shows e.g. in how we view interpretation.

Interpretation is usually seen as an attempt to get to the phantasies "behind" overt behavior, to the layers "below" representations at hand. The things we head at in interpretations (and in the whole psychoanalytic enterprise in fact) are inner reality. We think this reality is laid down in childhood. A case of example is the Sandlers' (1983, 1984) view of the psychoanalytic cure: through an investigation of the "present unconscious" we look towards the "past unconscious." Interpretation is the attempt to find this hidden, past and lost world. This is the aim of psychoanalysis. Interpretation is its vehicle.

This is the main picture of interpretation, and as such it is the psychoanalytical instrument per se - even when we do not use it, we head at it. This, at least, is the case in explicit clinical theory.

All contemporary groups described here challenge this view. The Boston group writes about "the something more" than interpretations. Fonagy and Target claim that classical interpretations do not work with the patients they describe. The Tähkäs suggest "empathic descriptions" instead of interpretations. A certain vacillation may, however, also be inferred. The Boston group says that interpretations have an important place in psychoanalysis (even though they claim that "the something more" is the thing that really changes patients). When Fonagy ponders about what to call the devices that really work, he comes to "small interpretations." It looks as if the modern authors would not want to abandon the interpretation concept.

However, looking at the contemporary picture, one may ask how radical the consequences regarding technique should be. Do we think that the authors describe only a specific group of patients (with 
borderline conditions), and that they do not touch on the treatment of neurotics? This can certainly be claimed. On the other hand it is also true that the authors do not seem to dare to draw all the technical conclusions they imply. Given the fact that we today rarely see pure neurotics, and that the "mostly neurotic ones" also have structural deficits all three groups speak of the patients we see in our daily practice. Add to this the fact that at least the Boston group clearly speaks about all patient groups. It may thus be that the three contemporary groups imply that interpretation should have a much more limited place than it has in explicit clinical theory. Other technical devices should take its place. This seems to be a major clinical consequence, not yet fully realized. Interpretation, as a route to a crystallized inner childhood world, should leave central stage for other clinical instruments.

The major consequence regarding theory follows from the clinical discussion.

Psychoanalysis has unquestionably been linked to the unconscious. As psychoanalysts we try to grasp the unconscious mind (be this configured as hidden behavioral impulses, phantasies, or internal object relations); this object defines us. Or: in psychoanalysis we turn from the outer world to the inner reality. This reality is the unconscious.

Interpretation and the unconscious are interdependent concepts. Due to the very object of psychoanalysis we need interpretations: since this object is the unconscious mind, we need a means to reach it; this means is interpretation. And the other way round: through interpretations we come to see the unconscious mind; without this instrument we cannot know its nature or even its existence. If the legitimacy of interpretations is questioned, does the same hold true for the unconscious? 
This seems to be the case. The Boston group says explicitly that the patient does not change through the reach of episodic but hidden contents - i.e., through the grasp of unconscious worlds (Stern et al. 1998, p. 903). Fonagy and the Tähkäs speak in the same vein: if one tries to facilitate new possibilities, an attempt to grasp the crystallized past within does not help. None of the authors deny its existence, but the unconscious has clearly become something at the margins of psychoanalysis. As a case of example, the change can be seen in the understanding of "psychic reality" (Holm Pedersen 2013). For Freud this reality was, as noted, the ungraspable past within. It was a synonym for the unconscious. For Fonagy and Target "psychic reality" is a dimension of subjective experience - a word for how our thoughts and feelings are real to us. This shows the move of object in psychoanalysis: from the unconscious mind to conscious experience.

If one draws all the conclusions of this last remark, the results seem unforeseeable. If we do not look for the unconscious, what do we search for? In case we forget about unconscious ideation, in which way does psychoanalysis differ from general psychology? There might certainly be defining differences anyhow, but they are not obvious, and need to be found. This seems a huge challenge.

Another issue is of course whether we at all should ask questions like these: even though contemporary psychoanalysts have turned from past to future, do we need to draw all conclusions? The inferences concerning interpretation and the unconscious seem unavoidable (given the description of modern authorships), but do we have to look in that direction? In psychoanalysis we are certainly used to many (and even contradictory) models; we take in new ways of thinking, but keep also the old ones. Flexibility and a spirit of inclusive acceptance may keep together our diverse discipline (Sandler 1983). It also needs to be stated 
that most psychoanalytic authors are not adherents to one model only; most use many ways of thinking. This is true also for the models here discussed: most analysts, at least in their clinical thinking, are both archaeologists and teleologists. As was noted, this is true also for Freud. Flexibility in the clinical situation is certainly a valuable thing. In thinking on theory, however, it may be good to separate models and see where they lead. Clarity, courage in making inferences, and thinking ahead may help us see things we otherwise would not see. A spirit of "anything goes" implies a risk of stagnation.

\section{A last word on possible dangers}

In the last section of his methodological testament Analysis terminable and interminable, Freud (1937a) discussed end points in psychoanalyses. Is termination a purely practical matter, something analyst and patient discuss and then simply decide upon? Or has the treatment a "natural" end? There are also more principal concerns. What do we aim for in psychoanalysis? Do we want to open up a new road, a possibility to always evaluate our relationship to realities in novel ways? This is the "analysis interminable", die unendliche Analyse. Or do we want to reach the very ground of our reality inside, der Fels, "rock bottom." This is analysis terminable, die endliche Analyse. In the end the question is thus where we want to turn - to the hidden past within, or the interminable possibility ahead? Contemporary authors seem to vote for the latter choice. From a slightly different perspective, Ricœur took up the issue already in 1970 (p. 433). He discussed the basis of interpretations. If we have only a teleological goal, a look forward, there is a risk that we get lost in interminable speculations. Every interpretation would be as good as any. The look 
back, the archaeological stance, means that we come to a certain reality (and not just any). This gives psychoanalysis a solid basis.

In this paper I have tried to present the contemporary picture and discuss some of its implications. The easy solution would naturally be that we need both past and future in psychoanalysis. As the picture today so clearly is for the look forward, Ricœur's warning may be worth noting. The implications of that, again, would require another paper.

\section{REFERENCES}

APEL, K.-O. (1971). Hermeneutik und Ideologiekritik [Hermeneutics and the critique of ideology]. Suhrkamp, Frankfurt.

BCPSG (2010). Change in psychotherapy. Norton, New York.

FONAGY, P. (1999). Memory and therapeutic action. Int J Psychoanal, 80: $215-223$.

FONAGY, P., Gergely, G., Jurist, E., Target, M. (2002). Affect regulation, mentalization, and the development of the self. Other Press, New York.

FONAGY, P., Target, M. (1996). Playing with reality: I. Int $J$ Psychoanal, 77: 217-33.

FONAGY P, Target, M. (2000). Playing with reality: III. Int $J$ Psychoanal, 81: 853-73.

FONAGY P, Target, M. (2007). Playing with reality: IV. Int $J$ Psychoanal, 88: 917-37.

FREUD, S. (1900). The interpretation of dreams. SE $I V-V$. Hogarth Press, London, pp. 1-715.

FREUD, S. (1901). The psychopathology of everyday life. SE VI. Hogarth Press, London, pp.1-296. 
FREUD, S. (1914). On narcissism: An introduction. SE XIV. Hogarth Press, London, pp. 67-107

FREUD, S. (1919). Lines of advances in psychoanalytic treatment. SE XVII. Hogarth Press, London, pp. 157-168.

FREUD, S. (1920). Beyond the pleasure principle. SE XVIII. Hogarth Press, London, pp. 1-64.

FREUD, S. (1923). The ego and the id. SE XIX. Hogarth Press, London, pp.1-66.

FREUD, S. (1927). The future of an illusion. SE XXI. Hogarth Press, London, pp. 1-56.

FREUD, S. (1930). Civilization and its discontents. SE XXI. Hogarth Press, London, pp. 57-146.

FREUD, S. (1937a). Analysis terminable and interminable. SE. XXIII. Hogarth Press, London, pp. 209-254.

FREUD, S. (1937b). Constructions in analysis. SE XXIII . Hogarth Press, London, pp.255-270

FREUD, S. (1938). An outline of psychoanalysis. SE XXIII . Hogarth Press, London, pp. 139-208.

GADAMER H-G (1975). Truth and method. Seabury Press, New York. HABERMAS, J. (1971). Knowledge and human interests. Heinemann, London.

HEGEL, F. (2018/1807) The phenomenology of spirit. Cambridge University Press, Cambridge.

HÖLDERLIN, F. (1952). Anmerkungen zum Oedipus. In: Gesammelte Werke, vol. 5. Kohlhemmer., Stuttgart.

HOLM PEDERSEN, S. (2013). Fonagy and Freud: Psychological versus psychic reality. Scand Psychoanal Rev, 36: 18-26.

RICOEUR, P. (1970). Freud and philosophy. Yale University Press, New Haven. 
SANDLER, J. (1983). Reflections on some relations between psychoanalytic concepts and psychoanalytic practice. Int $J$ Psychoanal, 64: 35-45.

SANDLER, J., Sandler, A.-M. (1983). The "second censorship", the "three box model" and some technical implications. Int $J$ Psychoanal, 64: 413-425.

SANDLER, J., SANDLER, A.-M. (1984). The past unconscious, the present unconscious, and interpretation of the transference. Psychoanal Inq, 4: 367-399.

STEINER, J. (1985). Turning a blind eye. Int Rev Psychoanal, 12: 161-72. STERN, D., Sander, L, Nahum, J., Harrsion, A., Lyons-Ruth, K., Morgan, A., Bruschweilerstern, N., Tronick, E. (1998). Non-interpretive mechanisms in psychoanalytic therapy: The "something more" than interpretation. Int J Psychoanal, 79: 903-921.

TÄHKÄ, R. (2000). Illusion and reality in the psychoanalytic relationship. Scand Psychoanal Rev, 23: 65-88.

TÄHKÄ, V. (1993). Mind and its treatment. International Universities Press, Madison.

TARGET, M., Fonagy, P. (1996). Playing with reality: II. Int $J$ Psychoanal, 77: 459-79.

VELLACOTT, P. (1971). Sophocles and Oedipus. Macmillan, London. ZACHRISSON, A. (2013). Oedipus the king: Quest for selfknowledge - denial of reality. Int J Psychoanal, 94: 313-331. 